\title{
Is Lumbar Puncture Alive and Well?
}

\begin{tabular}{|l|l|l}
\hline R.P. & Humphreys \\
\hline T. & Toronto \\
\hline
\end{tabular}

Pediatric neurosurgeons and their staff are being called upon to arbitrate the use of investigational lumbar puncture throughout the children's hospital. Neurosurgical residents are asked to visit the emergency room, infectious disease unit or neurology service to declare that it is 'safe' to perform a lumbar puncture which is required for all the usual reasons. As part of the process, information about the child's funduscopic examination and the most recent computed tomographic (CT) scan is made available. All of this seems to place the neurosurgeon in a contradictory position as historically they have adopted a very cautious attitude towards the procedure.

The reality is that 'septic workups' are a part of the milieu each day in a children's hospital, and the lumbar puncture is an essential component of that investigation. Infants who present with undiagnosed coma and seizures are managed as suffering from purulent meningitis for which the early diagnostic lumbar puncture is mandatory. While some might support a delay in cerebrospinal fluid (CSF) sampling in favor of broad spectrum antibiotics [1], others would argue that it is only proper to make an immediate and precise identification of the offending organism, if present.

The expected return on lumbar puncture and CSF analysis is clearly set out [2]. In the pediatric setting, its value in detecting infectious processes within the CSF is without question. Otherwise it is relegated to a secondary role in some children for analysis of sloughed neoplastic cells or in others with suspect demyelinating or degenerative disorders.

Perhaps some hoped that with the appearance of scanning and, more recently, magnetic. resonance imaging lumbar puncture would be rendered obsolete. But, the impact of CT has not significantly altered the role of the early diagnostic lumbar puncture [3]. There are still occasions when direct CSF sampling is a requisite. As a pre-

lude to that a thorough clinical evaluation and possibly CT scan will be required. And, even with the best of information disasters will occur. Gower and Grego [4] reviewed 4 patients who perished after lumbar puncture and all of whom had a 'normal' CT prior to the procedure. They conclude that 'while CT prior to LP will identify some patients at risk for cerebral herniation no absolute predictors of LP safety presently exist'.

In this issue, an extension of the lumbar puncture is recommended by Baldwin and Rekate for children with diffuse head injury. The authors have cautiously embarked on a program of 'controlled external lumbar drainage' in 5 children with intractable posttraumatic intracranial hypertension. Two of the 3 survivors achieved a 'good' outcome. Whatever the reader may think of the technique, the fact is that all of us are commonly asked about the safety of lumbar puncture. Perhaps individually we can do no better than to reflect on whether it 'will provide information which we do not now have and cannot obtain in any other way, and will that information significantly influence the treatment program we initiate?'. Lumbar puncture still appears to be alive and well when judiciously used.

\section{References}

1 Benjamin CM, Newton RW, Clarke MA, et all: Risks factors for death from meningitis. Br med J 1988;296:2O.

2 Wood JH: Cerebrospinal fluid: Techniques of access and analytical interpretation; in Wilkins RH, Rengachary SS (eds): Neurosurgery. New York, McGraw-Hill Book Company, 1985, pp 161-163.

3 Humphreys RP: Computed tomography and the early diagnostic lumbar puncture. Can Med Assoc J 1979; 121:150-151.

Gower DJ, Grego G: Death related to lumbar puncture. In Press. 